\title{
EMPIRICAL MODELING AND COMPARATIVE ANALYSIS OF LATHE MACHINE
}

\author{
Manoj Modi ${ }^{1 *}$, Veerendra Patil ${ }^{2}$, Abhishek Sharma $^{3}$, Vitthal Sharma ${ }^{4}$, Yash Joshi ${ }^{5}$ \\ Yash Joshi ${ }^{6}$, Adarsh Jain ${ }^{7}$, Sashant Chodhary ${ }^{8}$ \\ ${ }^{1 *}$ Department of Mechanical Engineering, Acropolis Institute of Technology and Research, Indore, India. \\ 2,3,4,5,6.7, Department of Mechanical Engineering, Acropolis Institute of Technology and Research, Indore, India.
}

\begin{abstract}
Lathe is a machine tool utilized for machining the cylindrical aspects, and also used for the turning of conical aspects etc. In this article, the dimensional analysis (D-A) methodology is utilized to develop the empirical model of material removal rate (MR-R). The various process factors involved in the experimental work are speed, feed, and depth-of-cut. Further, the created model has been approved by utilizing the test data's of turning with lathe machining, which are accessible at AITR, Indore to discover the relationship between's the assessed and test esteems.
\end{abstract}

Keywords - MR-R, Lathe Machine, DA, etc.

\section{INTRODUCTION}

Turning operation is one of the most basic machining processes in which the part is rotated while a single point cutting tool is moved parallel to the axis of rotation to cut and finish the work piece to obtain a desired shape and size, it can be done externally and internally on the work-piece and can be optimized through various parameters like cutting speed, depth-of-cut, feed-value, material-removal-rate, power drawn, etc. Fig. 1 and Fig.2 display the schematic diagram of turning operation in lathe machine and various parts of lathe machine respectively.

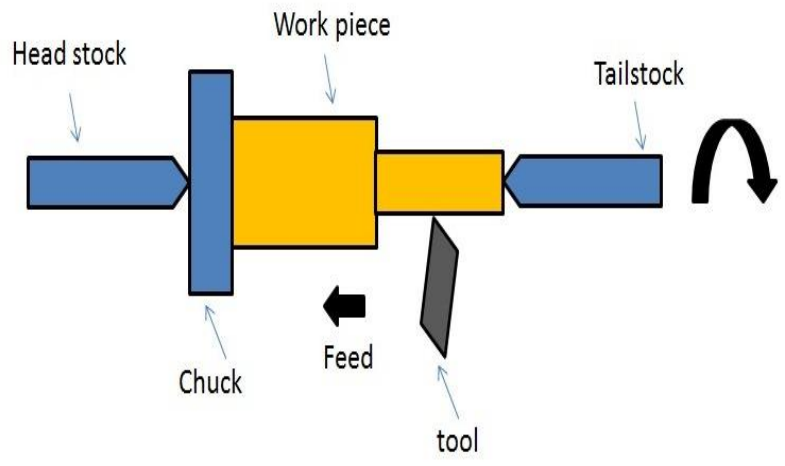

Fig.1- Schematic diagram of turning operation of lathe machine

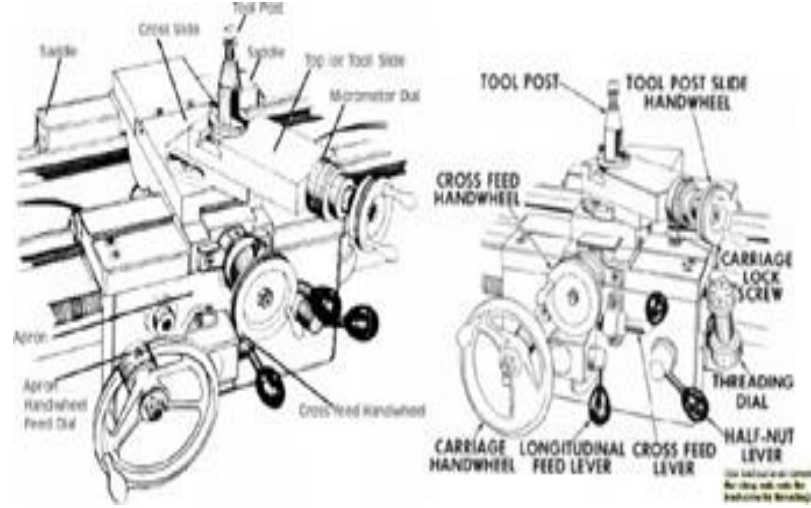

Fig.2. Various parts of lathe machine

"Abhang et al. (2012)" performed the experiments on EN-31 steel alloy with tungsten carbide inserts. They optimized the process factors involved in machining process through Taguchi and ANOVA method. "Lin et al. (2001)" received an abdicative system to develop a forecast model for surface harshness and cutting power. "Feng et al. (2002)" examined the effect on surface unpleasantness in get done with turning activity by building up an observational model through thinking about exogenous factors: work piece hardness, feed, cutting instrument point edge, depth-of-cut, spindle-speed, and cutting-time. "Suresh et al. (2002)" concentrated on machining mellow steel by TiC-covered tungsten-carbide cutting instruments for building up a surface harshness expectation model by utilizing Response-Surface-Methodology. "Kirby et al. (2004)" built up the forecast model for surface unpleasantness in turning activity. "Ahmed (2006)" built up the approach required for acquiring ideal procedure factors for expectation of surface harshness in Al-turning.

Based on the above literature review, it has been seen that modeling of process parameters in turning task is the field under progress. In this article, the dimensional analysis methodology is utilized to develop the empirical model of material removal rate (MR-R). Further, the created model has been approved by utilizing the trial information's of turning with lathe machining, which are accessible at AITR, Indore to watch the relationship between's the assessed and test esteems. 


\section{EXPERIMENTATION AND EMPIERICAL MODELING}

For the development of empirical model, dimensional analysis methodology is used in this article to correlate among MR-R and input machining turning factors. In this experimentation work, work-piece material was mild-steel and tool material was HS-S. In this test work Taguchi L9 O-A was used. Similarly, various types of Taguchi based O-A has been applied by the various researchers for modeling, planning, and conduction of experiments in their research works "Modi et al. (2009, 2012, 2013, 2019, and 2020)". The various input turning factors and response involved in this machining process are display in Table-1.

Table 1: Fundamental dimensions of input turning factor and

\begin{tabular}{|c|c|c|}
\hline \multicolumn{3}{|c|}{ response } \\
\hline S. No. & Parameters & Fundamental Dimension \\
\hline 1. & Speed & $\mathrm{M}^{0} \mathrm{~L}^{1} \mathrm{~T}^{-1}$ \\
\hline 2. & Feed & $\mathrm{M}^{0} \mathrm{~L}^{1} \mathrm{~T}^{-1}$ \\
\hline 3. & Depth of cut & $\mathrm{M}^{0} \mathrm{~L}^{1} \mathrm{~T}^{0}$ \\
\hline 4. & Density & $\mathrm{M}^{1} \mathrm{~L}^{-3} \mathrm{~T}^{0}$ \\
\hline 5. & Material removal rate & $\mathrm{M}^{1} \mathrm{~L}^{0} \mathrm{~T}^{-1}$ \\
\hline
\end{tabular}

Buckigham's $\pi$ theorem has been applied to develop the empirical model of MR-R.

$\pi_{1}=[\mathrm{F}]^{\mathrm{a}_{1}}[\mathrm{D} \quad 0 \mathrm{C}]^{b_{1}}[\rho]^{\mathrm{t}_{1}}[\mathrm{MR} \mathrm{R}]$

$M^{0} L^{0} T^{0}=\left[M^{0} L^{1} T^{-1}\right]^{4}\left[M^{0} L^{1} T^{0}\right]^{b}\left[M^{1} L^{-3} T^{0}\right]^{0}\left[M^{1} L^{0} T^{-1}\right](1)$

WE EQUATE THE POWERS OF M, L, AND T IN EQUATION 1. WE GET,

$$
\begin{aligned}
& \text { For } M \Rightarrow c_{1}+1=0 \Rightarrow c_{1}=-1 \\
& \text { For T } \Rightarrow-a_{1}-1=0 \Rightarrow a_{1}=-1 \\
& \text { For } L \Rightarrow a_{1}+b_{1}-3 c_{1}=0 \Rightarrow b_{1}+2=0 \Rightarrow b_{1}=-2 \\
& \pi_{1}=[F]^{-1}[D O C]^{-2}[\rho]^{-1}[M R R] \\
& \pi_{1}=\frac{M R R}{[F][D 0 C]^{2}[\rho]}
\end{aligned}
$$

SIMILARLY, WE SOLVE FOR $\Pi_{2}$,

$$
\pi_{2}=[\mathrm{F}]^{s_{1}}[\mathrm{D} O \mathrm{OC}]^{\mathrm{b}_{2}}[\rho]^{\mathrm{c}_{2}} \mathrm{~S}
$$

\section{$M^{0} L^{0} T^{0}=\left[M^{0} L^{1} T^{-1}\right]^{2}:\left[M^{0} L^{1} T^{0}\right]^{b}\left[M^{1} L^{-3} T^{0}\right]^{c}\left[M^{0} T^{0} T^{-1}\right]$ (2)}

WE EQUATE THE POWERS OF M, L, AND T IN EQUATION 2. WE GET,

$$
\begin{aligned}
& \text { For M } \Rightarrow c_{2}=0 \\
& \text { For L } \Rightarrow a_{2}+b_{2}-3 c_{2}=0 \Rightarrow a_{2}+b_{2}=0 \\
& \text { For T } \Rightarrow-a_{2}-1=0 \Rightarrow a_{2}=-1 \\
& \quad \Rightarrow a_{2}+b_{2}=0 \Rightarrow-1+b_{2}=0 \Rightarrow b_{2}=1 \\
& \pi_{2}=[F]^{-1}\left[\begin{array}{lll}
D & 0 & C
\end{array}\right]^{1}[\rho]^{0} \mathrm{~S} \\
& \pi_{2}=\frac{[D 0 C][S]}{[F]}
\end{aligned}
$$

According to B-Theorem, the dimensionless traits are related as follows

$\pi_{1}=\mathrm{f}\left(\pi_{2}\right)$

Where, $f$ is a function of dimensionless traits $\pi_{1}$ and $\pi_{2}$.

$\pi_{1}=\mathrm{P}\left(\pi_{2}\right)^{\mathrm{m}}$

The value of $\Pi_{1} \& \Pi_{2}$ is obtained by utilizing the practical data available at AITR Indore. The $\log -\log$ graph is drawn among $\Pi_{1} \& \Pi_{2}$ values. The values of $P$ and $m$ are determined through the graph. Fig. 3 displays the chart among $\Pi_{1} \& \Pi_{2}$ The final empirical model of MR-R is displayed by equation 3.

$$
\begin{aligned}
& \mathrm{MRR} /[\mathrm{F}][\mathrm{DOC}]^{2}[\rho]=1.51[\mathrm{~S} * \mathrm{DOC} / \mathrm{F}]^{-0.25} \\
& \mathrm{MRR}=1.51[\mathrm{~S} * \mathrm{DOC} / \mathrm{F}]^{-0.25} *[\mathrm{~F}][\mathrm{DOC}]^{2}[\rho]
\end{aligned}
$$

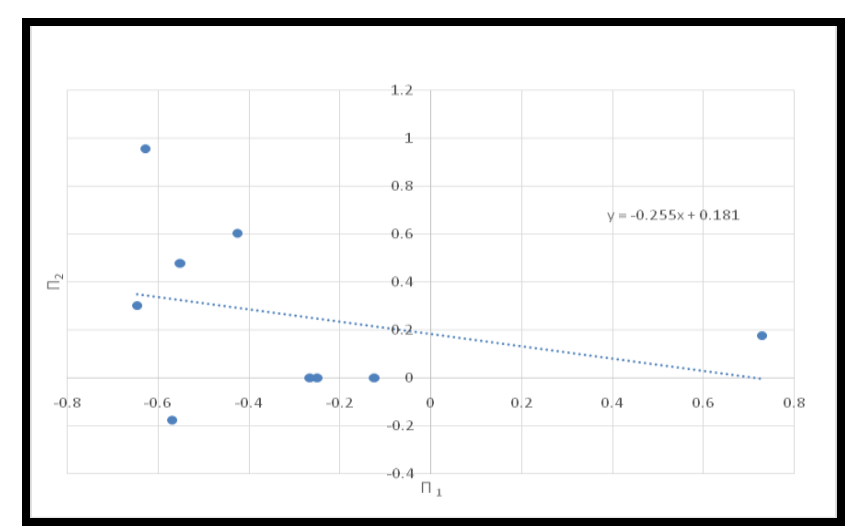

Fig.3. Chart among $\Pi_{1} \& \Pi_{2}$ parameters

\section{RESULTS AND DISCUSSION}

According to the plan, the experiments test results have gathered from AITR, Indore. The test and its response information are shown in Table 2. The Empirical model of MR-R has been created by utilizing DA technique. Fig. 4 


\section{International Journal of Engineering Applied Sciences and Technology, 2020 \\ Vol. 5, Issue 2, ISSN No. 2455-2143, Pages 435-438 \\ Published Online June 2020 in IJEAST (http://www.ijeast.com)}

displays the comparison among experimental and theoretical results of MR-R.

Table 2: Test results of turning operation

\begin{tabular}{|c|c|c|c|c|}
\hline S. No & Speed & Feed & DOC & MRR \\
\hline 1. & 810 & 12.7 & 0.5 & 0.006 \\
\hline 2. & 810 & 19.7 & 1.0 & 0.012 \\
\hline 3. & 810 & 26.7 & 1.5 & 0.017 \\
\hline 4. & 1280 & 12.7 & 1.0 & 0.009 \\
\hline 5. & 1280 & 19.7 & 1.5 & 0.018 \\
\hline 6. & 1280 & 26.7 & 0.5 & 0.027 \\
\hline 7. & 1750 & 12.7 & 1.5 & 0.013 \\
\hline 8. & 1750 & 19.7 & 0.5 & 0.026 \\
\hline 9. & 1750 & 26.7 & 1.0 & 0.049 \\
\hline
\end{tabular}

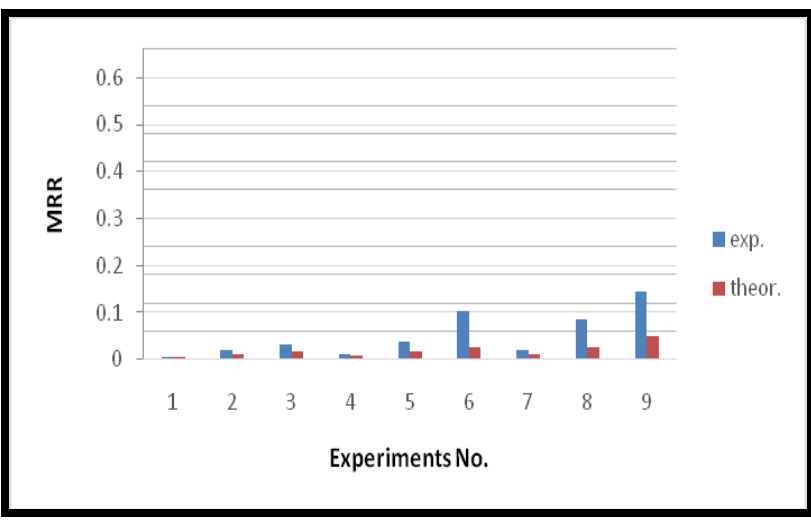

Fig.4. Comparative graph among experimental and theoretical results of MR-R

\section{CONCLUSION}

The below mentioned conclusion could be drawn from the results and discussion and the interpretation of figure 4.

1. The empirical model of MR-R is formulated by utilizing the DA method.

2. The comparative graph indicates that there is good agreement among experimental and theoretical values of MR$\mathrm{R}$ and both follow the identical trends.

3. The difference among theoretical and experimental value of MR-R at exp. No. 6, 8, and 9 is comparatively more. It is happened due to the availability of less numbers of test data's for development of empirical model of MR-R.

\section{REFERENCE}

[1] Abhang, L.B., Hameedullah, M. (2012). Optimization of machining parameters in steel turning operation by Taguchi method, Procedia Engineering, (pp. 40 - 48).

[2] Lin, W. S., Lee, B. Y., and Wu, C. L. (2001). Modeling the surface roughness and cutting force for turning",
Journal of Materials Processing Technology, Vol. 108, (pp. 286-293).

[3] Feng, C. X. and Wang, X. (2002). Development of Empirical Models for Surface Roughness Prediction in Finish Turning, International Journal of Advanced Manufacturing Technology, Vol. 20, (pp. 348 - 356).

[4] Suresh, P. V. S., Rao, P. V., and Deshmukh, S. G. (2002). A genetic algorithmic approach for optimization of surface roughness prediction model", International Journal of Machine Tools and Manufacture, Vol. 42, (pp. 675-680).

[5] Kirby, E. D., Zhang, Z., and Chen, J. C. (2004). Development of An Accelerometer based surface roughness Prediction System in Turning Operation Using Multiple Regression Techniques, Journal of Industrial Technology, Vol. 20 (4), (pp. 1-8).

[6] Ahmed S. G. (2006). Development of a Prediction Model for Surface Roughness in Finish Turning of Aluminium, Sudan Engineering Society Journal, Vol. 52 (45), (pp. 15).

[7] Modi, M., and Jha, S. (2009), Modeling and Analysis of Powder Mixed Electric Discharge Machining”, International Journal of Mechanical Engineering, Vol. 2 (2), (pp. 219-223).

[8] Modi, M., and Agarwal, G. (2012). Optimization of Electro-Discharge Diamond Surface Grinding Process Parameters with Multiple Performance Characteristics of Ti-6Al-4V using Grey-Taguchi approach, International Journal of Advanced Materials Research, Vols. 622-623, (pp. 14-18), DOI: https://doi.org/10.4028/www.scientific.net/AMR.622623.14.

[9] Modi, M., and Agarwal, G. (2013). Powder Mixed Electro Discharge Diamond Surface Grinding Process: Modelling, Comparative analysis and Multi-output optimization using Weighted Principal Components analysis", SV-Journal of Mechanical Engineering, Vol. 59 (12), (pp. 735-747), DOI: https://doi.org/10.5545/svjme.2013.1146.

[10] Modi, M., and Agarwal, G. (2013). Influence of Dielectric Jet flushing during Electro Discharge Diamond Surface Grinding process, International Journal of Advanced Materials Research, Vols. 652-654, (pp. 2187-2190), DOI:

https://doi.org/10.4028/www.scientific.net/AMR.652654.2187.

[11] Modi, M., and Agarwal, G. (2019). Integrated Statistical Methodology for optimizing machining parameters in $\mathrm{SiC}$ Powder Mixed - EDDSG process to machine Ti6Al4V, Materiali in Tehnologije / Materials and Technology Journal, Vol. 53 (3), (pp. 357-366), DOI: https://doi.org/10.17222/mit.2018.194. 
[12] Modi, M., Agarwal, G., and Chaugaonkar, S. D. (2019). Grey-WPCA Based parametric-optimization and modelling of chromium Powder Mixed Surface electro Discharge Diamond Grinding of Inconel 600 using RSM", Journal of Mechanical Engineering- Strojnícky časopis, Vol. 69 (4), (pp. 65 - 88), DOI: https://doi.org/ 10.2478/scjme-2019-0044.

[13] Modi, M., Agarwal, G., Patil, V., Bhatia, U. and Pancholi, R. (2019). Parametric optimization in Drilling of $\mathrm{Al} / \mathrm{SiC}$ composite using Taguchi Method", International Journal of Scientific \& Technology Research, Vol. 8 (9), (pp. 2019-22).

[14] Modi, M., Agarwal, G., Patil, V., Khare, A., Shukla, S. and Shankhla, A. (2019). Modeling and Analysis of Turning Process on Lathe Machine by Taguchi and ANOVA Approach", International Journal of Scientific \& Technology Research, Vol. 8 (10), (pp. 1466-70).

[15] Modi, M., Patil, V., Chougaonkar, S.D., Kaneherkar, P., Chandel, N., and Sharma, Y. (2020). Influence of viscosity variation on coefficient of friction in pipe flow with different pipe materials and flow rates using Taguchi Design Method, International Journal of Engineering and Advanced Technology, Vol. 9 (4), (pp. 1218-21).

[16] Modi, M., Patil, V., Chougaonkar, S. D., Kaneherkar, P., Chandel, N., Awasthy, J., Pawar, K. (2020). Impact of Viscosity Variation, and Flow Rate on Coefficient of Discharge in Venturimeter Utilizing Taguchi Methodology, International Journal of Engineering and Advanced Technology, Vol. 9 (4), (pp. 1838-40).

[17] Modi, M., Agarwal, G., Chaugaonkar, S.D., Bhatia, U., and Patil, V. (2020). Effect of Machine Feed Rate on Kerf-Width, Material Removal Rate, and Surface Roughness in Machining of $\mathrm{Al} / \mathrm{SiC}$ Composite Material with Wire Electrical Discharge Machine, Strojnícky časopis-Journal of Mechanical Engineering, Vol. 70 (1), (pp.81-88). 